Article

\title{
Perception of Time, Creative Attitudes, and Adoption of Innovations: A Cross-Cultural Study from Chinese and US College Students
}

\author{
Seung-Hee Lee ${ }^{1}$, Jane Workman ${ }^{1}$ and Kwangho Jung ${ }^{2, *}$ \\ 1 Fashion Design and Merchandising, 311 Quigley Hall, Southern Illinois University, Carbondale, \\ IL 62901, USA; leesh792@gmail.com (S.-H.L.); jworkman@siu.edu (J.W.) \\ 2 Korea Institute of Public Affairs, Graduate School of Public Administration, Seoul National University, \\ 1 Gwanak-ro, Gwanak-gu, Seoul 08826, Korea \\ * Correspondence: kwjung77@gmail.com; Tel.: +82-02-880-5626; Fax: +82-02-882-3998
}

Academic Editors: JinHyo Joseph Yun and Tan Yigitcanlar

Received: 31 August 2016; Accepted: 9 November 2016; Published: 18 November 2016

\begin{abstract}
This study explores how earlier (vs. later) adopters of innovation differ in time perception and creative attitudes, comparing Chinese and US college students. Research on the perception of time and creative attitudes is useful to understand how sustainability and creative collaboration might work together. Various relationships exist between different levels of innovation adoption groups and creative attitudes or perceptions of time. We found that earlier adopters scored higher on economic time and future time orientation. This may indicate that earlier adopters are sensitive about their planned schedule. Also, earlier adopters with a future time orientation are forward-thinking and anticipate the introduction of new styles, items, or events in the future. We also find that Chinese (vs. US) participants scored higher on creative capacity and creative collaboration but did not differ in general creative attitudes or creative risk-taking. For all participants from these two countries, earlier adopters (vs. later) scored higher on all aspects of creative attitudes. This study suggests academic and practical implications regarding sustainability issues. From an academic perspective, this study adds a new perspective to the literature about the relationships among time of adoption, time perception, creative attitudes, and cultural values, and is especially useful for how these four variables influence sustainability. From a practitioner perspective, this study provides information of how consumer values and attitudes in a developing economy (China) and a developed economy (US) might facilitate open innovation and induce sustainability.
\end{abstract}

Keywords: time perception; creative attitude; innovation; fashion adoption

\section{Introduction}

The concept of sustainability (i.e., meeting the needs of the present without depriving future generations of an ability to meet their needs) entails conscientious and pre-emptive innovation that creates balance among ecological resilience, economic prosperity, political justice, and cultural vibrancy [1]. Citizens of emerging economies (e.g., China) often aspire to living standards of more developed nations [2]. The combination of population increase and unmaintainable consumption levels presents challenges to sustainability [3].

Sustainability has become a hallmark for innovation around the world. Open innovation with sustainability comes from collaborative creative ideas with a long-term time horizon. Beyond consumerism and the profit maximization business model, citizens and firms need to learn sustainable consumption behavior and business strategy. However, enduring attitudes or perceptions can be barriers to open innovation with sustainability. For instance, sustainability implies a time 
context (past-present-future). Citizens and firms often prefer immediate economic benefits to long-term sustainable benefits. Consumption of goods and services involves individual choices that often involve short-term self-interests rather than long-term sustainable common goals. The growth model with a short-term time horizon and individual interest is far removed from the sustainable innovation model with a long-term orientation and creative collaboration. Relevant research questions about preferences for creative collaboration and a long-term time orientation are important to understand the diffusion of open innovations with regards to sustainability. In addition, attitudes and perceptions toward sustainability and open innovation are likely to vary during different stages of innovation adoption. The question about who creates and adopts open innovations for sustainability in a timely and expeditious manner is important.

Creativity is linked to innovation, which creates value. Creativity refers to mental and social processes, driven by conscious or unconscious insight, that yield new ideas, concepts, and associations [4]. Innovation is an outcome of the creative process, in which the ideas, concepts, and associations are applied to products, services, procedures, and processes that are desirable and viable within a specific context [4]. Innovation can be applied in many different contexts such as the automotive industry, mobile phone industry, computer industry, and the fashion industry, where creative attitudes and ideas are essential.

The ability to create novel and appropriate things or to innovate (i.e., build on new ideas) is critical to business success. However, at the introduction and early acceptance stages of an innovative product's life cycle, a vital influence is the behavior of consumer change agents, that is, individuals who are willing to be among the first to purchase and use the new product. According to Roger's adoption-diffusion model [5], interpersonal communication from professional change agents (individuals who influence clients' innovation adoption decisions in a direction deemed desirable by a change agency, to others is an important means by which innovations diffuse. Rogers' model of consumer groups depicts the adoption of innovations over time. Consumers who adopt innovations at different times in the product's lifestyle may differ in attributes such as creative attitudes or perceptions of time. For example, creative people are flexible, which enhances their ability to cope with change [6]. Creative people are willing to take sensible risks, to tolerate ambiguity, and to persist in solving problems [7]. These attributes may contribute to a willingness to adopt innovations earlier in the product lifecycle. Creative people are likely to adopt innovations earlier, whereas less creative people are likely to adopt innovations later. Furthermore, early adopters are likely to have a future time orientation compared with later adopters.

Time perceptions affect consumer choices about lifestyle and consumption [8]. Time perception may interact with other variables influencing consumer behavior, such as attitudes [9], emotions [10], and innovativeness [11]. Studying time orientations and creative attitudes is worthwhile in terms of understanding what contributes to favorable attitudes toward open innovation with sustainability. In addition, such relationships are likely to vary across countries and cultures. Different perspectives on time can predict consumer behaviors such as activity planning and materialism [12] that may vary across countries. There are different cultural models of time that may affect consumer behavior [13].

This study explores how the perception of time and creative attitudes vary from innovation adoption groups such as consumer change agents, early adopters, later adopters, and reluctant adopters. In addition, this study compares the relationships between innovation adoption groups and the perception of time, and creative attitudes in terms of Chinese and U.S. college students. More specifically, we use the context of fashion innovation to compare how U.S. and Chinese college students differ in time perception, creative attitudes, and adoption of innovations. There is no research that has examined the relationships among these variables. Therefore, the purpose of this study is to examine how earlier (vs. later) adopters of innovation differ in time perception and creative attitudes, comparing Chinese and US college students. 


\section{Literature Review}

\subsection{Adoption of Innovations and Time Perception}

The creation of innovative products is imperative for business survival because profits depend on the ability of innovative products to attract customers. Technological advances are truncating the life cycles of established products, fostering an increase in new products, resulting in the frequent introduction of new styles. The rate of product innovation has hit its highest point ever [14]. Successfully attracting the attention and support of consumer change agents helps ensure the success of innovative styles. When consumer change agents purchase new styles, the revenue needed to subsidize the costs of marketing a new fashion is provided.

One measure of an innovative style's success is the adoption of the style by a majority of consumers in a market. Indeed, a goal shared by many fashion businesses is to accelerate the time frame for the diffusion of new styles. Early adopters accelerate the adoption and diffusion of new fashions by disseminating information through word-of-mouth. Researchers have long been interested in diffusion of innovations $[15,16]$ and segmentation of consumers into time-of-adoption groups. "A major goal [of consumer behavior research] has been to understand how and why consumers vary with respect to the stage of a style's life cycle in which they are likely to adopt the style" [17]. Therefore, understanding how earlier versus later time-of-adoption groups differ in their personal traits such as creative attitudes and the perception of time is a critical topic of investigation for practical and scholarly reasons.

\subsubsection{Time Perception}

The perception of time is central to many consumer behavior issues. Time is ubiquitous in consumer situations: products are time-bound (e.g., especially fashion products) and buying decisions are time-based. Because most consumption and purchase decisions are individually based, understanding individual differences in time perceptions is central to understanding consumer behavior. One main focus of early research on time and consumer behavior was how consumers spend time on activities such as searching for information, acquisition, purchase decision, and consumption. Time perceptions are a blend of individual, socially, and culturally created traits that affect consumer behaviors (e.g., buying decisions when time is short or time devoted to competing activities; [18,19]).Time perceptions are important for such consumer concerns as delivery dates, warranty periods, appointments for personal services, assessment of product durability, or brand loyalty (i.e., repeatedly selecting the same brand time after time).

Dao [20] examined time perceptions and various consumer behaviors. Results showed that future and past time orientations affected the emphasis on design as a purchasing criterion. The preference for a quick return negatively influenced an emphasis on quality and price as purchasing criteria, and positively affected an emphasis on brand name as a key criterion for buying decisions. The effect of past orientation when purchasing certain products and services may be related to nostalgia [21]. Consumer behavior is affected by time as an element of opening hours, service schedules and duration, or waiting for service performance. Waiting is a component of consumer behavior, in pre-process (e.g., waiting to be helped by a sales associate), in-process (e.g., waiting to pay for a purchase), or post-process (e.g., waiting for delivery of purchases) [22]. Waiting time is both objective (chronological time) and subjective (related to the individual cognitive temporal system).

Market segmentation methods have used time styles as criteria to classify groups of consumers by time perception [23-25]. Some marketing concepts are time-based depictions such as the product lifecycle and Roger's [5] adoption-diffusion model.

\subsubsection{Time Perception and Time of Adoption}

Many consumer variables are affected by time-related issues such as the time spent shopping, search costs, and cognitive or emotional costs [26]. Earlier adopters (vs. later adopters) of fashion spent more time searching for information about fashion, made more clothing shopping trips, were 
more likely to attend fashion shows, read more fashion advertising, fashion magazines, and other women's magazines, and watched more television programs dealing with clothing styles [27-35]. Earlier (vs. later) adopters of fashion scored higher in convenience/time, recreational, and impulsive shopping orientations [36]. Therefore, earlier adopters are expected to differ from later adopters in perceptions of time. Hypothesis 1 was therefore proposed as,

- Hypotheses: H1a-h: Earlier (vs. later) adopters of fashion will differ in time perceptions such as (a) economic time; (b) non-organized time; (c) orientation toward the past; (d) orientation toward the future; (e) time anxiety; (f) tenacity; (g) preference for quick return; (h) time submissiveness.

\subsubsection{Culture and Time Perception}

The theory of cultural dimensions [37] asserts that socialization within different cultures results in dissimilarity between cultures in the endorsement of five broad cultural values: Individualism/Collectivism, Uncertainty Avoidance, Masculinity, Long-Term Orientation, and Power Distance. Individualism and collectivism indicate the extent of interdependence among members of a society, for example, family well-being versus personal interests [37]. In a collectivist culture such as China, concern with interdependent roles as group members is likely to result in beliefs that group norms are central. Conversely, in an individualist culture such as the US, individuals are likely to define their self-image in terms of $I$ rather than we. Hofstede's theory has been broadly applied to examine consumer behavior because consumer choices reflect their cultural values. For example, individual perceptions of time are affected by an individual's age, gender, role, and culture [38-40].

According to Ancona et al. [41], a temporal framework contains three interrelated categories: ideas of time (based mostly on culture), planning activities to time (situations and tasks), and individuals relating to time (i.e., beliefs, behavior, and adjustment). Time-laden activities (e.g., apparel shopping) display cultural, situational, and individual variability. Consumer attitudes toward time may affect the interpretation of advertising messages [19], especially in a cross-cultural perspective [42,43].

On Hofstede's [37] scale of cultural dimensions, long-term orientation reflects how linkages with a society's past are prioritized while coping with present and future challenges. China ranked 87/100 on long-term orientation indicating that China is a very pragmatic culture whose members demonstrate an ability to adapt traditions to changing conditions, perseverance in obtaining results, and a focus on education as a way to prepare for the future [44]. The US ranked 26/100on long-term orientation, a relatively low score, indicating a normative society whose members prefer to preserve time-honored customs and are suspicious of changes in society.

Shostya [45] examined the use of time among Chinese and US college students. Results showed that Chinese students spent more time on independent academic activities than US students. The Confucian cultural concept of learning strongly influences the value that Chinese students attach to learning, perhaps explaining the time they devote to academic activities and the strong motivation to achieve their educational goals compared with US students. Therefore, Chinese participants are expected to differ from US participants in time perceptions. Hypothesis 2 was therefore proposed as,

- H2a-h: Chinese and US participants will differ in perceptions of time such as (a) economic time; (b) non-organized time; (c) orientation toward the past; (d) orientation toward the future; (e) time anxiety; (f) tenacity; (g) preference for quick return; (h) time submissiveness.

\subsection{Creative Attitudes and Time of Adoption}

Flexibility is characteristic of creative people resulting in an ability to be comfortable with change [6]. Creative people display a willingness to solve problems, to take sensible risks, and to tolerate ambiguity [7]. According to the Snowflake Model of Creativity [46], creative people commonly have three cognitive traits (a strong commitment to a personal aesthetic, the ability to excel in finding solutions, and mental mobility) and three dispositional attributes (willing to take risks and to accept failure, objectivity, and inner motivation). A meta-analysis of research studies 
found the following traits associated with creative people: autonomy, introversion, achievement motivation, openness to new experiences, self-confidence, self-acceptance, social norm-doubting, and impulsivity [47]. Creative children were found to display disorganization, impulsivity, imagination, and nonconformity [48].

Earlier adopters of fashion display many attitudes related to creativity. For example, earlier (vs. later) adopters had a greater need for variety (mental stimulation), were higher on sensation seeking and experience seeking, were less susceptible to boredom, and were more innovative [49-52]. Earlier (vs. later) adopters scored higher on change, risk, and unusual stimuli subscales of the arousal seeking tendency scale [49]. Earlier (vs. later) adopters had an internal locus on control orientation, were less prone to boredom, and were highly capable in boredom coping [53]. Earlier (vs. later) adopters of fashion were higher on consumer impulsiveness [54]. Therefore, earlier adopters are expected to differ from later adopters in creative attitudes. Hypothesis 3 was therefore proposed as,

- H3 a-d: Earlier (vs. later) adopters of innovations will differ in creative attitudes such as: (a) general creative attitudes; (b) creative capacity; (c) creative collaboration; (d) creative risk-taking.

\subsection{Creative Attitudes and Culture}

Creativity is culturally bound-not just a mental process [55]. Economic, political, social, and cultural conditions affect the perceptions of what is considered to creative [56,57]. Creative designs can save money for manufacturers because it is estimated that $70 \%$ of the cost of a product depends on its design [58]. Compared with members of other cultures, U.S. individuals scored high in achievement motivation, autonomy, impulsiveness, openness to experience, nonconformity, self-confidence, and self-acceptance [59-67]. Zha, Walczyk, Griffith-Ross, Tobacyk and Walczyk [68] compared Chinese and American graduate students and found that American students (vs. Chinese) scored higher on four of the five components of divergent thinking (creative potential factors of fluency, originality, elaboration, and titles) but not flexibility. American students were more individualistic; Chinese were more collectivistic. Therefore, Chinese participants are expected to differ from US participants in creative attitudes. Hypothesis 4 was there proposed as,

- H4 a-d: Chinese and U.S. participants will differ in creative attitudes such as: (a) general creative attitudes; (b) creative capacity; (c) creative collaboration; (d) creative risk-taking.

\subsection{Culture and Time of Adoption}

The cultural dimension of uncertainty avoidance refers to the degree to which members of a culture consider ambiguous or unknown situations threatening and, therefore, have fostered beliefs and generated institutions to attempt to avoid these [37]. A low score of 30 (China) and 46 (US) on uncertainty avoidance indicates that members of both cultures are comfortable with ambiguity, exhibit acceptance of new ideas or innovative products, and are willing to try something new or different. Consumers who are comfortable with uncertainty and ambiguity may be willing to adopt new or innovative products early in the product lifecycle. Unlike other consumer products, a pronounced level of uncertainty surrounds fashion products because of their symbolic and expressive features [34]. Further, there is greater uncertainty associated with styles that are in the early (vs. later) stages of the fashion lifecycle. Because uncertainty and ambiguity dwindle as a style moves through its lifecycle, postponing purchases is one means for consumers who are uncomfortable with ambiguity to reduce their anxiety. Earlier adopters are comfortable with uncertainty and ambiguity as evidenced by their purchase of new products during the introductory and early acceptance stages.

Individualism/collectivism represents the extent to which members of a society are concerned with their personal interests and the welfare of their families [37]. Low scores on the individualism scale indicate that members of a society view themselves as part of a larger group. China scored 20 out of 100 indicating a collectivist culture while the US scored 91 out of 100 indicating an individualist culture [37]. In a collectivist culture such as China, individuals are likely to be concerned with their role 
as members of a group and are therefore likely to believe that group norms are relevant. Conversely, in an individualist culture such as the US, individuals are likely to be concerned with their own self-interests, be nonconformist, and interested in expressing their uniqueness.

Therefore, in countries with collectivist values (e.g., China), a relatively smaller group of fashion consumers may be willing to purchase products early in the life cycle. Conversely, in countries with individualist values (e.g., U.S.), relatively more consumers may be willing to purchase products early in the life cycle [34]. Indeed, Lee and Workman (2013) found that a smaller percentage of fashion consumers were early adopters in Korea (a collectivist culture) than in the US (an individualist culture). Hypotheses 5 and 6 were therefore proposed regarding differences between consumers in individualist (US) compared with collectivist (China) countries.

- H5: Chinese and U.S. participants will differ in time of adoption.

- H6: A smaller percentage of Chinese consumers will be earlier adopters (i.e., consumer change agents and early adopters) than US consumers.

The purpose of this study is to examine how earlier (vs. later) adopters of innovation differ in time perception and creative attitudes, comparing Chinese and US college students. Figure 1 depicts the framework for this study.

\begin{tabular}{|c|c|}
\hline \multicolumn{2}{|c|}{$\begin{array}{l}\text { Innovation Adoption, Time Perception and Creative Attitudes: } \\
\text { Comparing Chinese and U.S College Students }\end{array}$} \\
\hline & Time Perception \\
\hline & $\begin{array}{l}\text { Economic time } \\
\text { Non-organized time } \\
\text { Orientation toward the past } \\
\text { Orientation toward the future } \\
\text { Time anxiety } \\
\text { Tenacity } \\
\text { Preference for quick return }\end{array}$ \\
\hline \multicolumn{2}{|l|}{\begin{tabular}{|l|} 
Innovation Adoption Group \\
\end{tabular}} \\
\hline \multirow[t]{3}{*}{$\begin{array}{l}\text { Consumer change agents } \\
\text {. Early adopters } \\
\text {. Late adopters } \\
\text {. Reluctant adopters } \\
\end{array}$} & \\
\hline & Creative Attitude \\
\hline & $\begin{array}{l}\text { General creativity } \\
\text { Creative capacity } \\
\text { Creative collaboration } \\
\text { Creative risk-taking }\end{array}$ \\
\hline
\end{tabular}

Figure 1. Research Framework.

\section{Method}

\subsection{Participants}

Participants in this study were 209 American students from Southern Illinois University in the United States and 193 Chinese students from Lanzhou University in China. It was assumed that the majority of the students were of middle class socioeconomic status. In the U.S., in 2014, there were 21.6 million college students ( $58 \%$ female; $42 \%$ male), with $\$ 163$ billion used in discretionary purchases from their estimated $\$ 545$ billion in expenditures [69,70]. In 2010, in China, there were about 31 million college students [71]. Therefore, due to their sheer volume, U.S. and Chinese male and female university 
students were considered an important sample for an investigation of time perception, creative attitudes, and adoption of innovations. These students are in a time of their life that is important to identity formation, where they are making decisions about what they believe and value and applying these beliefs and values to consumer choices-choices that will influence their consumer behavior in the future. Within a particular culture, this period of life is also significant in the maturation of time perceptions and creative attitudes. In cultures that differ in cultural dimensions (e.g., individualism and collectivism, long-term orientation, uncertainty avoidance), individuals' perceptions and attitudes are expected to differ. Thus, differences in adoption of innovations, time perception, and creative attitudes between China and US consumers are expected.

\subsection{Procedure}

After approval by the Institutional Review Board, data were collected in large lecture classes from U.S. and Chinese university students who took about $20 \mathrm{~min}$ to complete the questionnaire. Participants circled a number on a 7 -point scale $(7=$ strongly agree; $1=$ strongly disagree $)$ to indicate the degree of agreement with each item. The questionnaire contained demographic items, measures of time styles [12,23], creative attitudes [4], and fashion innovativeness and opinion leadership [71].

\subsection{Materials}

The Time Styles Scale, developed by Usunier and Valette-Florence [12,23], was used to measure individual perceptions of time. The time styles scale has four main dimensions, with two subdimensions in each higher order factor; items are measured with a 7-point Likert-type scale. Items in each sub-dimension were summed to arrive at a score on each time variable. The first dimension is linearity and economics of time: economic time (e.g., "I like to have a definite schedule and stick to it") and non-organized time (e.g., "I hate following a schedule"). The second dimension measures temporal orientations: orientation toward the past (e.g., "I feel nostalgic about the past") and orientation toward the future (e.g., "I think a lot about what my life will be some day"). The third dimension is obedience to time: time submissiveness (e.g., "I am almost never late for work or appointments") and time anxiety (perceived usefulness of time; e.g., "I am bored by my day-to-day activities"). The fourth dimension is temporal persistence: tenacity (e.g., "When I begin a project, I don't like to stop it until it is finished") and preference for quick return (e.g., "I would prefer doing several very small projects than one very large one"). Nomological validity was determined by the scale's ability to predict values, individual activity planning, and attitudes towards waiting time, buying, and consumption behavior. Scale reliability exceeded the desired level of 0.7 , and all items demonstrated adequate convergent validity. The Times Styles Scale is reliable and valid. Cross-cultural replications showed the relevance of time styles dimensions in different national/cultural environments, such as China, Germany, Tunisia, and Vietnam.

The Creative Attitudes Scale was adapted from Serrat [4] and is comprised of four conceptual aspects of creativity: general creative attitudes (e.g., "I pursue imaginative ideas"); creative capacity (e.g., "I identify the creative value of diverse thinking styles, and incorporate this diversity in teams"); creative collaboration ("I actively look for group members whose thinking styles differ from my own"); and creative risk-taking (e.g., "I support people taking intelligent risks and do not penalize them when they fail").

Time-of-adoption was measured by the Fashion Innovativeness and Opinion Leadership self-report measure [72]. The scale has established reliability, content validity, comparability across studies, and extensive use in research. Scores can range from 0 to 24 (higher scores indicate earlier adoption). A $t$-test, comparing Chinese $(M=14.25)$ and $U S(M=14.73)$ participants, on scores of Fashion Innovativeness and Opinion Leadership was not significant [ $t(399 \mathrm{df})=1.07, p<0.286]$. Therefore, participants were classified into time-of-adoption groups based on the mean and standard deviation of scores as follows: (a) consumer change agents scored more than one standard deviation (SD) above the mean of the 6 -item scale (more than $14.5+4.56=19.06$ ); $(\mathrm{b})$ early adopters scored between the 
mean and one SD above the mean (less than or equal to 19.06 and more than 14.5); (c) late adopters scored between the mean and one SD below the mean (less than or equal to 14.5 and greater than 9.94); (d) reluctant adopters scored more than one SD below the mean (less than or equal to 9.94). This procedure resulted in $72(18.0 \%)$ consumer change agents, 137 (34.2\%) early adopters, 117 (29.2\%) late adopters, and $75(18.7 \%)$ reluctant adopters. A crosstabs analysis with country (China, US) and time-of-adoption groups (consumer change agents, early adopters, late adopters, reluctant adopters) yielded a non-significant Pearson's chi-square statistic [chi-square ( $3 \mathrm{df})=1.03, p<0.793$ ].

\subsection{Statistical Analysis}

We conducted descriptive statistics, Cronbach's alpha reliability, MANOVA (Multivariate Analysis of Variance), ANOVA (Analysis of Variance), and Pearson's Chi-square test in order to analyze the data. Descriptive statistics report the degree of time perception and creative attitudes of Chinese and U.S. college students. MANOVA and ANOVA procedures illustrate the mean differences in time perception and creative attitudes of four types of innovation adoption groups including consumer change agents, early adopters, late adopters, and reluctant adopters. In addition, mean differences in time perception and creative attitudes are analyzed between Chinese and U.S. college students.

\section{Empirical Results}

Participants in this study were 209 US and 193 Chinese university students. There were 185 females and 215 males with a mean age of 21.13 (range 17-32) from a variety of majors (e.g., engineering, sports management, fashion, architecture, business). Ethnicity in the US sample was 38 (18.2\%) African American, 11 (5.25\%) Asian/Asian American, 144 (68.9\%) Caucasian, 12 (5.74\%) Hispanic/Latino, and $4(2.0 \%)$ otherwise classified.

Cronbach's alpha reliability was acceptable, ranging from 0.60 to 0.90 (see Table 1). One sub-dimension of the Time Styles Scale was not reliable (time submissiveness) so it was not used in the analysis. Hypothesis 1 and 2 were revised to eliminate time submissiveness.

Table 1. Descriptive statistics and reliability for measures.

\begin{tabular}{ccccc}
\hline & Mean & SD & Observed Range & Reliability Cronbach's $\alpha$ \\
\hline Time perception & & & & \\
\hline Economic time & 18.70 & 4.52 & $4-28$ & 0.864 \\
Non-organized time & 10.97 & 3.14 & $3-21$ & 0.627 \\
Orientation toward the past & 17.70 & 4.47 & $4-28$ & 0.821 \\
Orientation toward the future & 19.65 & 4.77 & $2-28$ & 0.906 \\
Time anxiety & 14.61 & 4.24 & $4-28$ & 0.747 \\
Tenacity & 13.67 & 2.90 & $4-21$ & 0.736 \\
Preference for quick return & 7.74 & 2.01 & $2-14$ & 0.624 \\
\hline Creative attitudes & & & & \\
\hline General creativity & 7.96 & 1.42 & $2-10$ & 0.742 \\
Creative capacity & 11.49 & 2.12 & $3-15$ & 0.772 \\
Creative collaboration & 7.16 & 1.69 & $2-10$ & 0.600 \\
Creative risk-taking & 11.33 & 1.86 & $6-15$ & 0.858 \\
\hline Time of adoption & 14.50 & 4.56 & $4-24$ &
\end{tabular}

MANOVA was conducted with time-of-adoption groups (consumer change agents, early adopters, late adopters, reluctant adopters) and culture (China, US) as the independent variables. Dependent variables were seven sub-dimensions of time perception (economic time, non-organized time, past orientation, future orientation, time anxiety, time tenacity, and preference for quick return). MANOVA revealed significant effects for time-of-adoption groups $[F(8,387)=4.39, p<0.000]$ and for culture $[F(8,385)=20.79, p<0.000]$ on the dependent variables. ANOVA revealed significant effects for time-of-adoption group on three of the seven time variables: economic time, future orientation, and 
time anxiety (see Table 2). Student-Newman-Keuls post hoc test $(p>0.05)$ revealed that earlier adopters differed significantly from later adopters on economic time, future time orientation, and time anxiety. Earlier adopters scored higher on economic time and future time orientation, but later adopters scored higher on time anxiety.

Table 2. ANOVA results of time of adoption groups for scores on time perceptions.

\begin{tabular}{|c|c|c|c|c|}
\hline Scale & Mean (SD) & Mean Square & $F$ & $p<$ \\
\hline Economic time & & 118.43 & 6.36 & 0.000 \\
\hline Consumer change agents & $20.08(4.49)$ & & & \\
\hline Early adopters & $19.47(4.25)$ & & & \\
\hline Late adopters & $18.04(4.34)$ & & & \\
\hline Reluctant adopters & $17.44(4.83)$ & & & \\
\hline Non-organized time & & 16.94 & 1.78 & 0.150 \\
\hline Consumer change agents & $10.90(3.56)$ & & & \\
\hline Early adopters & $10.60(2.80)$ & & & \\
\hline Late adopters & $11.49(3.12)$ & & & \\
\hline Reluctant adopters & $10.96(3.26)$ & & & \\
\hline Past orientation & & 3.99 & 0.21 & 0.890 \\
\hline Consumer change agents & $17.94(4.45)$ & & & \\
\hline Early adopters & $17.69(4.06)$ & & & \\
\hline Late adopters & $17.57(4.74)$ & & & \\
\hline Reluctant adopters & $17.73(4.71)$ & & & \\
\hline Future orientation & & 49.75 & 2.57 & 0.050 \\
\hline Consumer change agents & $20.33(4.64)$ & & & \\
\hline Early adopters & $20.09(4.34)$ & & & \\
\hline Late adopters & $19.33(4.98)$ & & & \\
\hline Reluctant adopters & $28.57(5.13)$ & & & \\
\hline Time anxiety & & 36.33 & 2.35 & 0.072 \\
\hline Consumer change agents & $13.93(4.31)$ & & & \\
\hline Early adopters & $14.61(4.34)$ & & & \\
\hline Late adopters & $14.46(3.73)$ & & & \\
\hline Reluctant adopters & $15.71(4.47)$ & & & \\
\hline Tenacity & & 6.61 & 0.79 & 0.500 \\
\hline Consumer change agents & $13.81(2.82)$ & & & \\
\hline Early adopters & $13.88(2.56)$ & & & \\
\hline Late adopters & $13.34(2.86)$ & & & \\
\hline Reluctant adopters & $13.61(3.03)$ & & & \\
\hline Preference for quick return & & 2.84 & 0.72 & 0.540 \\
\hline Consumer change agents & $7.39(2.11)$ & & & \\
\hline Early adopters & $7.73(1.89)$ & & & \\
\hline Late adopters & $7.81(1.89)$ & & & \\
\hline Reluctant adopters & $7.93(2.24)$ & & & \\
\hline
\end{tabular}

Note: Degree of freedom were $[3,387]$ for all variables.

- Hypotheses: H1a-h: Earlier (vs. later) adopters of innovations will differ in time perceptions such as (a) economic time; (b) non-organized time; (c) orientation toward the past; (d) orientation toward the future; (e) time anxiety; (f) tenacity; (g) preference for quick return. H1a, H1d, and H1e were supported; H1b, H1c, H1f, and H1g were not supported.

ANOVA revealed significant effects of culture on five of the seven time variables: economic time, non-organized time, past orientation, future orientation, and time anxiety (see Table 3). 
US participants (vs. Chinese) scored higher on economic time and future orientation. Chinese participants (vs. US) scored higher on non-organized time, past orientation, and time anxiety.

- H2a-h: Chinese and U.S. participants will differ in perceptions of time such as (a) economic time; (b) non-organized time; (c) orientation toward the past; (d) orientation toward the future; (e) time anxiety; (f) tenacity; (g) preference for quick return. Hypotheses 2a, b, c, d, and e were supported.

Table 3. ANOVA results of culture (China and U.S.) for scores on time perception.

\begin{tabular}{|c|c|c|c|c|}
\hline Scale & Mean (SD) & Mean Square & $F$ & $p<$ \\
\hline Economic time & & 18.63 & 18.90 & 0.000 \\
\hline China & $17.72(4.03)$ & & & \\
\hline U.S. & $19.78(4.73)$ & & & \\
\hline Non-organized time & & 9.53 & 8.85 & 0.003 \\
\hline China & $11.47(2.53)$ & & & \\
\hline U.S. & $10.52(3.56)$ & & & \\
\hline Past orientation & & 19.40 & 13.81 & 0.000 \\
\hline China & $18.53(4.26)$ & & & \\
\hline U.S. & $16.95(4.49)$ & & & \\
\hline Future orientation & & 19.37 & 61.42 & 0.000 \\
\hline China & $17.77(3.85)$ & & & \\
\hline U.S. & $21.37(4.89)$ & & & \\
\hline Time anxiety & & 15.48 & 51.17 & 0.000 \\
\hline China & $16.18(3.40)$ & & & \\
\hline U.S. & $13.22(4.40)$ & & & \\
\hline Tenacity & & 8.36 & 1.93 & 0.166 \\
\hline China & $13.44(2.32)$ & & & \\
\hline U.S. & $13.87(3.32)$ & & & \\
\hline Preference for quick return & & 3.96 & 0.01 & 0.930 \\
\hline China & $7.70(1.69)$ & & & \\
\hline U.S. & $7.76(2.25)$ & & & \\
\hline
\end{tabular}

Note: Degree of freedom were $[1,392]$ for all variables.

MANOVA was conducted with time-of-adoption groups (consumer change agents, early adopters, late adopters, reluctant adopters) and culture (China, US) as the independent variables. Dependent variables were four creative attitudes (general creativity, creative capacity, creative collaboration, and creative risk-taking). MANOVA revealed significant effects for the time-of-adoption group $[F(4,391)=4.32, p<0.002]$ and for culture $[F(4,389)=6.15, p<0.000]$ on the dependent variables.

ANOVA revealed significant effects for the time-of-adoption group on all four creative attitude variables (see Table 4). Student-Newman-Keuls post hoc test $(p>0.05)$ revealed that earlier adopters differed significantly from later adopters on general creativity, creative capacity, creative collaboration, and creative risk-taking. Earlier adopters scored higher on these measures of creative attitudes than later adopters.

- H3 a-d: Earlier (vs. later) adopters of innovations will differ in creative attitudes such as: (a) general creative attitudes; (b) creative capacity; (c) creative collaboration; (d) creative risk-taking. H3 a-d was supported. 
Table 4. ANOVA results of time of adoption groups for scores on creative attitudes.

\begin{tabular}{ccccc}
\hline Scale & Mean (SD) & Mean Square & $\boldsymbol{F}$ & $\boldsymbol{p}<$ \\
\hline General creativity & & 7.66 & 3.88 & 0.009 \\
\hline Consumer change agents & $8.32(1.16)$ & & & \\
Early adopters & $8.06(1.32)$ & & & \\
Late adopters & $7.91(1.42)$ & & 3.48 & 0.016 \\
Reluctant adopters & $7.52(1.71)$ & & & \\
\hline Creativity Capacity & & 15.25 & & \\
\hline Consumer change agents & $11.88(2.15)$ & & & \\
Early adopters & $11.65(1.97)$ & & & \\
Late adopters & $11.50(1.98)$ & & & \\
Reluctant adopters & $10.83(2.42)$ & & & \\
\hline Creative collaboration & & & & \\
\hline Consumer change agents & $7.40(2.03)$ & & & \\
Early adopters & $7.32(1.45)$ & & & \\
Late adopters & $7.14(1.70)$ & & & \\
Reluctant adopters & $6.64(1.63)$ & & & \\
\hline Creative risk-taking & & & & \\
\hline Consumer change agents & $11.76(1.87)$ & & & \\
Early adopters & $11.32(1.78)$ & & & \\
Late adopters & $11.38(1.97)$ & & & \\
Reluctant adopters & $10.81(1.74)$ & & & \\
\hline Note: Degree of freedom were [3,391] for all variables. & & \\
\hline
\end{tabular}

ANOVA revealed significant effects of culture on two of the four creative attitudes variables: creative capacity and creative collaboration (see Table 5). US participants (vs. Chinese) scored lower on creative capacity and creative collaboration.

- $\quad$ H4 a-d: Chinese and U.S. participants will differ in creative attitudes: (a) general creative attitudes; (b) creative capacity; (c) creative collaboration; (d) creative risk-taking. Hypothesis $4 \mathrm{~b}$ and c were supported; 4a and d were not supported.

ANOVA was conducted to examine time-of-adoption between the two cultures. ANOVA revealed no significant effect for culture $[F(1,399)=1.14, p<0.286]$ on time-of-adoption: US participants $(\mathrm{M}=14.736)$ and Chinese participants (14.249). Higher scores indicate earlier adoption. H5: Chinese and U.S. participants will differ in time-of-adoption of innovations. H5 was not supported.

A chi-square test of time-of-adoption groups was conducted to examine hypothesis six. The chi-square test was not significant $(\mathrm{df}=3$; Pearson Chi-Square $=1.033 ; p<0.793)$. Percentages were as follows: (a) consumer change agents US ( $n=41 ; 19.7 \%)$; Chinese $(n=31 ; 16.1 \%)$; (b) early adopters US $(n=68 ; 32.7 \%)$; Chinese $(n=69 ; 35.8 \%)$; (c) late adopters US $(n=60 ; 28.8 \%)$ Chinese $(n=57 ; 29.5 \%)$; and $(\mathrm{d})$ reluctant adopters US $(n=39 ; 18.8 \%)$; Chinese $(n=36 ; 18.7 \%)$.

- H6: A smaller percentage of Chinese consumers will be earlier adopters (i.e., consumer change agents and early adopters) than US consumers. H6 was not supported. 
Table 5. ANOVA results of culture (China and U.S.) for scores on creative attitude.

\begin{tabular}{|c|c|c|c|c|}
\hline Scale & Mean (SD) & Mean Square & $F$ & $p<$ \\
\hline General creativity & & 1.21 & 0.61 & 0.430 \\
\hline China & $7.92(1.35)$ & & & \\
\hline U.S. & $8.01(1.49)$ & & & \\
\hline Creativity capacity & & 18.68 & 4.27 & 0.040 \\
\hline China & $11.69(1.79)$ & & & \\
\hline U.S. & $11.30(2.37)$ & & & \\
\hline Creative collaboration & & 30.34 & 11.11 & 0.001 \\
\hline China & $7.41(1.28)$ & & & \\
\hline U.S. & $6.91(1.97)$ & & & \\
\hline Creative risk-taking & & 0.41 & 0.12 & 0.730 \\
\hline China & $11.27(1.65)$ & & & \\
\hline U.S. & $11.37(2.05)$ & & & \\
\hline
\end{tabular}

Note: Degree of freedom were $[1,389]$ for all variables.

\section{Discussion}

The purpose of this study was to examine how earlier (vs. later) adopters of innovation differ in time perception and creative attitudes, comparing Chinese and US college students. Results indicated differences in time perception and creative attitudes among earlier (vs. later) adopters of innovation and between Chinese and US college students. Each hypothesis will be discussed separately.

Hypothesis one predicted that the time of adoption of innovations would be affected by time perceptions such as: (a) economic time; (b) non-organized time; (c) orientation toward the past; (d) orientation toward the future; (e) time anxiety; (f) tenacity; and (g) preference for quick return. Results showed that time-of-adoption groups differed in the following aspects of time perception: economic time, orientation toward the future, and time anxiety. Earlier adopters (vs. later adopters) had a stronger reaction to linearity and economic time, a stronger orientation toward the future, and were less anxious about time. Earlier adopters appear not to worry about spending time shopping or in conducting an information search or other activities associated with fashion (e.g., fashion shows, reading fashion magazines, etc.). The future orientation indicates that they are eager and willing to try new products and are comfortable with ambiguity or uncertainty. Economic time indicates priority of scheduling time for activities that are considered important consumer behaviors such as searching for information, shopping, purchasing, and post-purchase evaluation.

Hypothesis 2 predicted that Chinese and US participants would differ in perceptions of time such as: (a) economic time; (b) non-organized time; (c) orientation toward the past; (d) orientation toward the future; (e) time anxiety; (f) tenacity; and (g) preference for quick return. Results revealed that Chinese and US students differed in the following aspects of time perception: economic time, non-organized time, orientation toward the past, orientation toward the future, and time anxiety. Graham (1981) proposed different cultural models of time [13] These results concurred with Graham's proposal, that is, US students scored higher on economic time and orientation toward the future while Chinese students scored higher on non-organized time, orientation toward the past, and time anxiety.

Hypothesis three predicted that earlier (vs. later) adopters of innovations would differ in creative attitudes such as: (a) general creative attitudes; (b) creative capacity; (c) creative collaboration; (d) creative risk-taking. Time-of-adoption groups did differ in all four measures of creative attitudes: general creative attitudes; creative capacity; creative collaboration; and creative risk-taking. Earlier adopters (vs. later) scored higher on all aspects of creative attitudes. As noted in the literature review, earlier adopters of fashion display many attitudes related to creativity. Results are consistent with earlier research (e.g., $[49,50]$ ) showing that earlier (vs. later) adopters were more innovative and 
expressed greater interest in sensation seeking and experience seeking. Earlier (vs. later) adopters had more positive attitudes toward change and risk [49] and were more impulsiveness [54].

Hypothesis four predicted that Chinese and U.S. participants would differ in creative attitudes such as: (a) general creative attitudes; (b) creative capacity; (c) creative collaboration; (d) creative risk-taking. Chinese (vs. U.S.) participants scored higher on creative capacity and creative collaboration but did not differ in general creative attitudes or creative risk-taking. Differences in creative collaboration between two groups may indicate that those in collectivist cultures such as China are more likely to cooperate with others or work together as group members than those in individualist cultures. Results of the current study contrast with those of Zha et al. [68], who found that American students (vs. Chinese) scored higher on the creative potential factors of fluency, originality, elaboration, and titles. The difference in results could be due to the manner in which creativity was measured.

Hypothesis five predicted that Chinese and U.S. participants would differ in time of adoption of innovations. Hypothesis six predicted that a smaller percentage of Chinese consumers would be earlier adopters (i.e., consumer change agents and early adopters) than US consumers. Results showed that Chinese and U.S. participants did not differ in the time of adoption of innovations and there was no significant difference in the percentage of consumers in each time-of-adoption group. It was anticipated that Chinese participants would have a smaller percentage of earlier adopters than US participants because of cultural values associated with collectivism. However, Chinese culture also has a high tolerance for ambiguity, leading to acceptance of innovative products and a willingness to try something new or different. These results contrast with Lee and Workman [73] who found that Korean consumers in a collectivist culture (vs. an individualist culture-US) did have a smaller percentage of earlier adopters. One explanation for this disparity may be the cultural value of uncertainty avoidance which appears to carry more weight than collectivism or individualism in determining time-of-adoption. Two different collectivist cultures had different results on time-of-adoption presumably because of uncertainly avoidance-South Korea's score of 85/100 on uncertainty avoidance indicates a low level of tolerance for uncertainty [37].

\section{Implications and Suggestions for Further Research}

\subsection{Implications for Innovation Adoption, Creative Attitudes, and Cultural Values}

Based on these results, this study provides academic and practical implications. From an academic perspective, this study adds a new perspective to the literature about relationships among time of adoption, time perception, creative attitudes, and cultural values. From a practitioner perspective, this study provides information for fashion marketers or retailers that will help them understand earlier adopters' consumption behavior. For example, the results revealed that earlier adopters scored higher on economic time and future orientation. This may indicate that earlier adopters are sensitive about their planned schedule; therefore, that they might expect prompt delivery of new products or service from corporations. Also, earlier adopters have a future orientation; they are forward-thinking and anticipate the introduction of new styles or items or events in the future. These findings suggest that various new types of sustainable products with pro-environmental elements may significantly attract early adopters in a global Chinese market. If early adopter groups in China participate in the consumption of sustainable products, it might be easier to diffuse sustainable products to other global market areas and to strengthen the legitimacy of sustainable products.

Further, these results may help international marketers or retailers to adapt their new brand marketing strategies for different cultures. Currently, in a process of homogenization, collectivist cultures such as China have modified their values to more closely follow individualist cultures. Based on the results of the current study, cultural values (e.g., collectivism) seem to be a definitive force among Chinese students in terms of time perception and creative attitudes. Research on how past time orientation and an attitude favoring creative collaboration in Chinese college students can influence the future workforce at global rising companies in China for sustainability, and open 
innovation can provide useful academic and practical implications. Thus, a better understanding of consumers in a variety of cultures is called for if international corporations or marketers want to succeed. For example, Chinese consumers scored higher in past orientation than U.S. consumers. This may indicate that Chinese consumers consider their past purchasing experiences as indicative of future service. If past experiences or past memories about a certain brand are positive, they may retain positive images about the brand and, as loyal customers, be willing to spread reports of their satisfaction to other customers. Conversely if they had negative experiences, they might shop less frequently. So, for Chinese consumers, positive customer service experiences may be an important component of brand or store loyalty. What are the implications of all these interesting findings in the Chinese and U.S. business ecosystem for sustainability and open innovation? It is important to provide positive experiences of sustainable products for Chinese consumer groups because Chinese consumers with positive experiences buying sustainable products can more actively consume them than U.S. consumers. This implies that the Chinese government can facilitate and expand sustainable consumption for Chinese consumers through implementing public policy that encourages suppliers and consumers to participate in the sustainable consumption process. In addition, results showed earlier adopters scored higher on creative attitudes than later adopters. This indicates that earlier adopters have an appreciation for imaginative new styles, interesting information, and inventive activities, searching for new ways to experience innovativeness. Methods to attract earlier adopting customers and diminish the risk of boredom will entail providing something new for customers to experience. This implies that if suppliers provide sustainable products with new innovative styles, early adopters among Chinese consumers will consume them, which can contribute to promoting sustainable consumption and building a dense global market toward sustainability. Based on this process, the Chinese economy may not pursue short-term growth but sustainability.

In summary, our preliminary findings provide important implications for public policy makers, suppliers, and consumers to diffuse sustainability issues in global market. Our analyses identify a significant relationship of sustainability with creativity and time preference. Our findings suggest that it is crucial to provide sustainable products with new innovative styles for Chinese consumers, and then to encourage them to tell others about their positive experiences buying them at an early stage of consumption. We can create a virtuous sustainable consumption cycle surrounding the processes of providing pro-environmental products with new innovative styles, consuming them with positive experiences, sharing the positive experience and knowledge about the sustainable products, and institutionalizing the mechanism of supply and demand for sustainable products.

\subsection{Limitaions and Further Research Agenda}

This comparative study between China and U.S. college students has various limitations in terms of data quality, model specification, and statistical analysis. Further research is required to consider the following issues in order to develop a more systematic theory about time preference, creativity, and innovation attitude across various countries and cultures.

First, we used survey data from only two countries: China and the United States. Further research is required to expand this survey to other Asian countries such as South Korea, Japan, Turkey, and Thailand, to Latin America, and to European countries. More cross-nationally expanded data will provide an opportunity to examine cultural differences in creative attitudes and time perception in terms of time-different innovation adopters. In addition, the sample data we used covers only two universities including Lanzhou University in China and Southern Illinois University in America. These two universities are ranked at the middle level of all the universities in each country and may only partially represent normal college students. Further study is required to expand the study to college students at other various levels of universities in these two countries. A more representative sample for each country can contribute to increasing the validity of the empirical findings of how creative attitudes and time perception are associated with early or later adopters for new products. 
Second, attitudes toward creativity and time perception may differ between various college majors. For instance, college students with business and economics majors might be more likely to be early adopters than those with other majors. College students with majors of liberal arts may have a more non-organized time attitude than those with majors of law and business. College students with majors of art and design may have a more imaginative and diverse attitude than those with majors of science and math. These major differences in creativity and time perception can provide important implications for how to design and teach college curriculum to intensify time perception and innovation attitude toward sustainability.

Third, a survey of the general population (excluding college students) can provide a more complete picture of relationships between different acceptance levels of innovation adopters, perception of time, and creative attitudes. The extension of the survey scope to the general population of consumers and to different countries will allow a more systematic exploration of innovation adoption, time perception, and creative attitudes.

Last, our statistical analyses, relying on survey data, provided mean differences in creativity and time perception in Chinese and American college students, rather than the effect size of creativity and time preference on adopting new products. The sample in this paper represents one time survey data without controlling key potential factors that may confuse the size of mean differences in our MANOVA model. Those confounding factors may increase or decrease the mean differences in our research model. For instance, not only age, gender, income, and culture but also various experiences in our daily lives such as unemployment, political participation, and economic crisis significantly influence individual attitudes toward time perception and creativity. In order to identify the effects of these factors, further study, relying on longitudinal data and experimental data, is required to conduct a more systematic analysis with a high level of statistical control or experimental control.

Author Contributions: Seung-Hee Lee and Jane Workman conceived and designed the research study. Kwangho Jung conductedthe survey in China; Seung-Hee Lee, Jane Workman and Kwangho Jung analyzed the data; Kwangho Jung contributed analysis tools; Seung-Hee Lee, Jane Workman and Kwangho Jung wrote the paper.

Conflicts of Interest: The authors declare no conflict of interest.

\section{References}

1. Magee, L.; Scerri, A.; James, P.; Thom, J.A.; Padgham, L.; Hickmott, S.; Deng, F.; Cahill, F. Reframing social sustainability reporting: Towards an engaged approach. Environ. Dev. Sustain. 2013, 15, 225-243. [CrossRef]

2. Booming Nations. Threaten Earth. BBC News, 12 January 2006.

3. Cohen, J.E. Human Population: The Next Half Century. In Science Magazine's State of the Planet 2006-2007; Kennedy, D., Ed.; Island Press: London, UK, 2006; pp. 13-21.

4. Serrat, O. Harnessing creativity and innovation in the workplace. In Knowledge Solutions; Asian Development Bank: Manila, Philippines, 2009; pp. 61-72.

5. Rogers, E.M. Diffusion of Innovations, 4th ed.; Free Press: New York, NY, USA, 1995.

6. Runco, M.A. Creativity. Annu. Rev. Psychol. 2004, 55, 657-687. [CrossRef] [PubMed]

7. Sternberg, R.J. The nature of creativity. Creativity Res. J. 2006, 18, 87-98. [CrossRef]

8. Settle, R.B.; Alreck, P.L.; Glasheen, J.W. Individual time orientation and consumer lifestyles. Adv. Consum. Res. 1978, 5, 313-319.

9. Homer, P.; Kahle, L.R. A structural equation test of the value-attitude-behavior hierarchy. J. Pers. Soc. Psychol. 1988, 54, 638-646. [CrossRef]

10. Laverie, D.A.; Kleine, R.E., III; Kleine, S.S. Linking emotions and values in consumption experiences: An exploratory study. Adv. Consum. Res. 1993, 20, 70-75.

11. Roehrich, G.; Valette-Florence, P.; Rapacchi, B. Combined Influence of Personal Value Systems, Involvement and Innovativeness on Innovative Consumer Behavior: An Application on Perfume Purchase, Is Marketing Keeping up with the Consumer? Available online: https:/ / www.esomar.org/ (accessed 11 November 2016).

12. Usunier, J.-C.; Valette-Florence, P. The Time Styles Scale: A review of developments and replications over 15 years. Time Soc. 2007, 16, 333-366. [CrossRef] 
13. Graham, R.J. The role of perception of time in consumer research. J. Consum. Res. 1981, 7, 335-342. [CrossRef]

14. Boundless. Speed of Innovation. Available online: https://www.boundless.com/management/textbooks/ boundless-management-textbook/organizational-culture-and-innovation-4/adapting-and-innovating36/speed-of-innovation-195-1047/ (accessed on 18 June 2015).

15. Hawkins, D.; Best, R.J.; Coney, K.A. Consumer Behaviour: Building Marketing Strategy; McGraw Hill: Boston, MA, USA, 1998.

16. Rogers, E.M. Diffusion of Innovations; Free Press: New York, NY, USA, 1962.

17. Kaiser, S.B. The Social Psychology of Clothing: Symbolic Appearances in Context, 2nd ed.; Fairchild: New York, NY, USA, 1997.

18. Feldman, L.P.; Hornik, J. The Use of Time: An integrate Conceptual Model. J. Consum. Res. 1981, 7, 407-419. [CrossRef]

19. Kaufman, C.F.; Lane, P.M.; Lindquist, J.D. Exploring More than 24 Hoursa Day: A Preliminary Investigation of Polychronic Time Use. J. Consum. Res. 1991, 18, 392-401. [CrossRef]

20. Dao, T. Influence of Time Styles and Perceived Self-Efficacy on Purchase Decision Styles: A Comparison of French and Vietnamese Consumers Regarding Audiovisual Products. Available online: http://www.theses. fr/2005REN1G011 (accessed 11 November 2016).

21. Havlena, W.J.; Holak, S.L. The Good Old Days: Observations on Nostalgia and Its Role in Consumer Behavior. In Advances in Consumer Research; Holman, R.H., Salomon, M.R., Eds.; Association for Consumer Research: Provo, UT, USA, 1991; pp. 323-329.

22. Maister, D.H. The Psychology of Waiting Lines. In The Service Encounter; Czepiel, J.A., Solomon, M.R., Surprenant, C.F., Eds.; Lexington Books: Lexington, MA, USA, 1985; pp. 113-123.

23. Usunier, J.-C.; Valette-Florence, P. Perceptual time patterns ("Time-Styles"): A psychometric scale. Time Soc. 1994, 3, 219-241. [CrossRef]

24. Valette-Florence, P.; Ferrandi, J.-M.; Usunier, J.-C. Time and consumer behavior: The case of mobile phones. Revue Fr. Gest. 2001, 132, 112-118.

25. Brodowsky, G.H.; Anderson, B.B.; Meilich, O.; Schuster, C.P.; Venkatesan, M.V. If Time is Money, is it a Common Currency? A Cross-Cultural Study of Time Attitudes. In American Marketing Association Summer Educators Conference Proceedings; Grewal, D., Levy, M., Krishman, R., Eds.; American Marketing Association: Chicago, IL, USA, 2006; pp. 378-379.

26. Zeithaml, V.A. Consumer perceptions of price, quality, and value: A means-end model and synthesis of evidence. J. Mark. 1988, 52, 2-22. [CrossRef]

27. Goldsmith, R.E.; Heitmeyer, J.R.; Freiden, J.B. Social values and fashion leadership. Cloth. Text. Res. J. 1991, 10,37-45. [CrossRef]

28. Goldsmith, R.; Flynn, L.R. Identifying innovators in consumer product markets. Eur. J. Mark. 1992, 26, 42-55. [CrossRef]

29. Goldsmith, R.E.; Freiden, J.B.; Kilsheimer, J.C. Social values and female fashion leadership: A cross-cultural study. Psychol. Mark. 1993, 10, 399-412. [CrossRef]

30. Flynn, L.R.; Goldsmith, R.E.; Eastman, J.K. Opinion leaders and opinion seekers: Two new measurement scales. J. Acad. Mark. Sci. 1996, 24, 137-147. [CrossRef]

31. Goldsmith, R.E.; Flynn, L.R.; Moore, M.A. The self-concept of fashion leaders. Cloth. Text. Res. J. 1996, 14, 242-248. [CrossRef]

32. Goldsmith, R.E.; Moore, M.A.; Beaudoin, P. Fashion innovativeness and self-concept: A replication. J. Prod. Brand Manag. 1999, 8, 7-18. [CrossRef]

33. Vernette, É. Targeting women's clothing fashion opinion leaders in media planning: An application for magazines. J. Advert. Res. 2004, 44, 90-107. [CrossRef]

34. Quigley, C.J., Jr.; Notarantonio, E.M. A cross-cultural comparison of United States and Austrian fashion consumers. J. Euromark. 2009, 8, 233-244. [CrossRef]

35. Stanton, J.; Paolo, D. Information overload in the context of apparel: Effects on confidence, shopper orientation and leadership. J. Fash. Mark. Manag. 2012, 16, 454-476. [CrossRef]

36. Workman, J.E.; Cho, S. Gender, fashion consumer groups, and shopping orientation. Fam. Consum. Sci. Res. J. 2012, 40, 267-283. [CrossRef]

37. Hofstede, G. Culture's Consequences; Sage: Beverly Hills, CA, USA, 1980.

38. Davies, G.; Omer, O. Time Allocation and Marketing. Time Soc. 1996, 5, 253-268. [CrossRef] 
39. Fraisse, P. Perception and Estimation of Time. Annu. Rev. Psychol. 1984, 35, 1-36. [CrossRef] [PubMed]

40. Bergadaà, M. The Role of Time in the Action of the Consumer. J. Consum. Res. 1990, 17, 289-302. [CrossRef]

41. Ancona, D.G.; Okhuysen, G.A.; Perlow, L.A. Taking Time to Integrate Temporal Research. Acad. Manag. Rev. 2001, 26, 512-529.

42. Manrai, L.A.; Manrai, A. Effect of Cultural Context, Gender, and Acculturation on Perception of Work versus Social/Leisure Time Usage. J. Bus. Res. 1995, 32, 115-128. [CrossRef]

43. Brodowsky, G.H.; Anderson, B.B. A cross cultural study of consumer attitudes toward time. J. Glob. Mark. 2000, 13, 93-109. [CrossRef]

44. Itim International. Geert Hofstede Cultural Dimensions. 2009. Available online: http://geert-hofstede.com/ national-culture.html (accessed on 23 May 2016).

45. Shostya, A. The use of time among college students: A U.S.-China comparison. Int. J. Educ. 2015, 7, $195-208$. [CrossRef]

46. McAleer, N. On creativity: The roots of inspirations. Omni 1989, 11, 42.

47. Feist, G.J. A meta-analysis of the impact of personality on scientific and artistic creativity. Personal. Soc. Psychol. Rev. 1998, 2, 290-309. [CrossRef] [PubMed]

48. Cropley, A.J. More Ways than One: Fostering Creativity; Ablex: Norwood, NJ, USA, 1994.

49. Kwon, Y.-H.; Workman, J.E. Relationship of optimum stimulation level to fashion behavior. Cloth. Text. Res. J. 1996, 14, 249-256. [CrossRef]

50. Muzinich, N.; Pecotich, A.; Putrevu, S. A model of the antecedents and consequents of female fashion innovativeness. J. Retail. Consum. Serv. 2003, 10, 297-310. [CrossRef]

51. Stanforth, N. Fashion innovators, sensation seekers, and clothing individualists. Percept. Motor Skills 1995, 81, 1203-1210. [CrossRef]

52. Workman, J.E.; Johnson, K.K.P. Fashion opinion leadership, fashion innovativeness, and need for variety. Cloth. Text. Res. J. 1993, 11, 60-64. [CrossRef]

53. Workman, J.E.; Studak, C.M. Relationships among fashion consumer groups, locus of control, boredom proneness, boredom coping and intrinsic enjoyment. Int. J. Consum. Stud. 2007, 31, 66-75. [CrossRef]

54. Cardoso, P.R.; Costa, H.S.; Novais, L.A. Fashion consumer profiles in the Portuguese market: Involvement, innovativeness, self-expression and impulsiveness as segmentation criteria. Int. J. Consum. Stud. 2010, 34, 638-647. [CrossRef]

55. Csikszentmihalyi, M. Implications of a systems perspective for the study of creativity. In Handbook of Creativity; Sternberg, R.J., Ed.; Cambridge University Press: New York, NY, USA, 1999; pp. 313-335.

56. Simonton, D.K. Creativity, leadership and chance. In The Nature of Creativity; Sternberg, R.J., Ed.; Cambridge University Press: New York, NY, USA, 1988; pp. 384-426.

57. Simonton, D.K. Greatness: Who Makes History and Why; Guilford: New York, NY, USA, 1994.

58. Munroe, A.S. Is your design a life sentence? Mach. Des. 1995, 17, 156.

59. Barone, T.N. A comparative study of value perceptions and normative rule compliance of Malaysian and American secondary school students. Diss. Abstr. Int. Sect. A Hum. Soc. Sci. 1999, 59, 3397.

60. Chatterjee, M.M. Ethnicity and personality: Variations in personality as a function of cultural differences in social desirability. Diss. Abstr. Int. Sect. B Sci. Eng. 1995, 55, 5061.

61. Crott, H.W.; Baltes, P.B. Desirability of personality dimensions: Auto- and hetero-perceptions by American and German college students. J. Soc. Psychol. 1973, 91, 15-27. [CrossRef] [PubMed]

62. Ghosh, P.K. Similarities and differences in personality characteristics of managers across culture: Indian. J. Appl. Psychol. 1975, 12, 65-70.

63. Jamison, R.N. Differences in personality between American and English children. Pers. Individ. Differ. 1984, 5, 241-244. [CrossRef]

64. Margalit, B.A.; Mauger, P.A. Cross-cultural demonstration of orthogonality of assertiveness: Comparison between Israel and the United States. J. Pers. Soc. Psychol. 1984, 46, 1414-1445. [CrossRef]

65. Peng, Y. Primary and secondary control in American and Chinese-American adults: Cross-cultural and life-span developmental perspectives. Diss. Abstr. Int. Sect. B Sci. Eng. 1995, 55, 3037.

66. Sagie, A.; Elizur, D.; Yamauchi, H. The structure and strength of achievement motivation: A cross-cultural comparison. J. Organ. Behav. 1996, 17, 431-444. [CrossRef]

67. Tang, N.M. Some psychoanalytic implications of Chinese philosophy and child-rearing practices. Psychoanal. Study Child. 1992, 47, 371-389. [PubMed] 
68. Zha, P.; Walczyk, J.J.; Griffith-Ross, D.A.; Tobacyk, J.J.; Walczyk, D.F. The impact of culture and individualism-collectivism on the creative potential and achievement of American and Chinese adults. Creativity Res. J. 2006, 18, 355-366. [CrossRef]

69. U.S. College Explorer. 2014. Available online: http://www.refuelagency.com/wp-content/themes/ refuelagency/college_explorer/college_explorer_2014_high_level_review.pdf (accessed on 24 May 2016).

70. National Center for Education Statistics. 2015. Available online: http://nces.ed.gov/fastfacts/display.asp? id=372 (accessed on 24 May 2016).

71. China's Higher Education Students Exceed 30 Million—People's Daily. Available online: http://en.people. cn/90001/98649/7315789.html (accessed on 11 November 2016).

72. Hirschman, E.; Adcock, W. An examination of innovative communicators, opinion leaders, and innovators of men's fashion apparel. In Advances in Consumer Research; Hunt, H.K., Ed.; Association for Consumer Research: Ann Arbor, MI, USA, 1978; pp. 303-314.

73. Lee, S.-H.; Workman, J.E. Gossip, self-monitoring, and fashion consumer groups. Cloth. Text. Res. J. 2013, 31, 67-80. [CrossRef]

(C) 2016 by the authors; licensee MDPI, Basel, Switzerland. This article is an open access article distributed under the terms and conditions of the Creative Commons Attribution (CC-BY) license (http:/ / creativecommons.org/licenses/by/4.0/). 